\title{
Defect engineering of BCZT-based piezoelectric ceramics with high piezoelectric properties
}

\author{
Xinjian $\mathrm{WANG}^{a}$, Yu HUAN ${ }^{a, *}$, Yixuan $\mathrm{ZHU}^{a}$, Peng $\mathrm{ZHANG}^{a}$, Wenlong YANG ${ }^{a}$, \\ Peng $\mathrm{LI}^{b}$, Tao $\mathrm{WEI}^{a}$, Longtu $\mathrm{LI}^{c}$, Xiaohui $\mathrm{WANG}^{c}$ \\ ${ }^{a}$ School of Material Science and Engineering, University of Jinan, Jinan 250022, China \\ ${ }^{b}$ School of Materials Science and Engineering, Liaocheng University, Liaocheng 252000, China \\ ${ }^{c}$ State Key Laboratory of New Ceramics and Fine Processing, School of Materials Science and Engineering, \\ Tsinghua University, Beijing 100084, China
}

Received: June 11, 2021; Revised: July 25, 2021; Accepted: August 9, 2021

(c) The Author(s) 2021.

\begin{abstract}
The intrinsic conduction mechanism and optimal sintering atmosphere of $\left(\mathrm{Ba}_{0.85} \mathrm{Ca}_{0.15}\right)\left(\mathrm{Zr}_{0.1} \mathrm{Ti}_{0.9}\right) \mathrm{O}_{3}(\mathrm{BCZT})$ ceramics were regulated by Mn-doping element in this work. By Hall and impedance analysis, the undoped BCZT ceramics exhibit a typical n-type conduction mechanism, and the electron concentration decreases with the increasing oxygen partial pressure. Therefore, the undoped ceramics exhibit best electrical properties (piezoelectrical constant $d_{33}=585$ $\mathrm{pC} \cdot \mathrm{N}^{-1}$, electro-mechanical coupling factor $k_{\mathrm{p}}=56 \%$ ) in $\mathrm{O}_{2}$. A handful of Mn-doping element would transfer the conduction mechanism from n-type into p-type. And the hole concentration reduces with the decreasing oxygen partial pressure for Mn-doped BCZT ceramics. Therefore, the Mn-doped ceramics sintered in $\mathrm{N}_{2}$ have the highest insulation resistance and best piezoelectric properties $\left(d_{33}=\right.$ $\left.505 \mathrm{pC} \cdot \mathrm{N}^{-1}, k_{\mathrm{p}}=50 \%\right)$. The experimental results demonstrate that the Mn-doping element can effectively adjust the intrinsic conduction mechanism and then predict the optimal atmosphere.
\end{abstract}

Keywords: BCZT ceramics; Mn-doping; different sintering atmosphere; p/n-type conduction mechanism; defect engineering

\section{Introduction}

Lead zirconate titanate based piezoelectric ceramics have been used in many electronic devices, such as sensors, actuators, and transducers [1], because of their extraordinary electrical properties and excellent piezoelectric response (piezoelectrical constant $d_{33} \approx$ $600 \mathrm{pC} \cdot \mathrm{N}^{-1}$ ) [2,3]. However, lead is toxic, and may cause severe human diseases or environmental problems

\footnotetext{
* Corresponding author.

E-mail: mse_huany@ujn.edu.cn
}

[4]. Therefore, it is crucial to explore new lead-free piezoelectric systems to replace lead-based piezoelectric materials. In recent years, lead-free piezoelectric ceramics such as $\mathrm{BaTiO}_{3}(\mathrm{BT})$ [5,6], $(\mathrm{Bi}, \mathrm{Na}) \mathrm{TiO}_{3}(\mathrm{BNT})[7,8]$, $(\mathrm{K}, \mathrm{Na}) \mathrm{NbO}_{3}$ (KNN) [9,10], have been extensively studied. Nevertheless, the piezoelectric properties of lead-free piezoelectric ceramics could not compare with the lead zirconate titanate based ceramics.

Therefore, many methods, such as improvement of preparation method [11], optimization of sintering process [12-14], doping strategy, texturing $[15,16]$, were applied to construct morphotropic phase 
boundary (MPB) and polycrystalline phase boundary at room temperature. Excitingly, Liu and Ren [17] modified BT ceramics by introducing $\mathrm{Ca}^{2+}$ and $\mathrm{Zr}^{4+}$ ions to construct the rhombohedral-orthorhombictetragonal coexistence at room temperature. And the prepared $\left(\mathrm{Ba}_{0.85} \mathrm{Ca}_{0.15}\right)\left(\mathrm{Zr}_{0.1} \mathrm{Ti}_{0.9}\right) \mathrm{O}_{3}(\mathrm{BCZT})$ ceramics exhibited an ultrahigh piezoelectric constant $\left(d_{33} \approx\right.$ $\left.620 \mathrm{pC} \cdot \mathrm{N}^{-1}\right)$. Subsequently, the BCZT-based ceramics attracted tremendous attention and were identified as an ideal candidate for preparing the multilayer piezoelectric devices. To save cost, the base metal (Ni or $\mathrm{Cu}$ ) should replace the precious metals $(\mathrm{Ag}, \mathrm{Pt}$, or Pd) as internal electrodes [18]. However, the base metal electrode will oxidize under high oxygen partial pressure. Therefore, the BCZT-based ceramics should be co-sintered under low oxygen partial pressure with base metal internal electrodes.

There are very few reports on BCZT ceramics sintered under different atmospheres [19-21], and almost none of them illustrate the intrinsic conductivity mechanism. This work adjusted the defect structure of BCZT ceramics by Mn-doping elements. The intrinsic conduction mechanism of BCZT ceramics was systematically elucidated by Hall test and impedance spectroscopy. Our study demonstrated that the undoped BCZT ceramics exhibit an n-type conduction mechanism, whereas the Mn-doped BCZT ceramics exhibit a p-type conduction mechanism. Therefore, it is inferred that the optimal sintering atmosphere for undoped and Mn-doped ceramics is $\mathrm{O}_{2}$ and $\mathrm{N}_{2}$, respectively. Subsequently, the experimental results verified the prediction.

\section{Experimental}

$0.25 \mathrm{~mol} \% \mathrm{MnCO}_{3}$ doped $\left(\mathrm{Ba}_{0.85} \mathrm{Ca}_{0.15}\right)\left(\mathrm{Ti}_{0.9} \mathrm{Zr}_{0.1}\right) \mathrm{O}_{3}$ $(\mathrm{BCZT})$ and pure BCZT powders were prepared using the conventional solid-state reaction method. Barium carbonate $\left(\mathrm{BaCO}_{3}, 99 \%\right.$; Shanghai Macklin Biochemical Co., Ltd., China), calcium carbonate $\left(\mathrm{CaCO}_{3}, 99 \%\right.$; Sinopharm Group Co., Ltd. , China), titanium dioxide ( $\mathrm{TiO}_{2}, 99 \%$; Tianjin Fuchen Chemical reagents Co., Ltd., China), barium zirconium oxide $\left(\mathrm{BaZrO}_{3}, 99 \%\right.$; Alfa Aesar Co., Ltd., China), and manganese carbonate $\left(\mathrm{MnCO}_{3}\right.$, 99.95\%; Shanghai Macklin Biochemical Co., Ltd., China) were used as starting materials. The raw materials were weighed according to nominal stoichiometric composition and then homogenized in a planetary mill for $12 \mathrm{~h}$ using ethanol as the milling medium. The obtained slurry was dried thoroughly and then calcined at $1180{ }^{\circ} \mathrm{C}$ for $3 \mathrm{~h}$. After that, the mixtures were ball milled for another $12 \mathrm{~h}$. The powders were then compacted into pellets with a diameter of $10 \mathrm{~mm}$ and a thickness of $1 \mathrm{~mm}$ by uniaxial pressing in a stainless-steel die using a polyvinyl butyral as binder. The Mn-doped BCZT specimens were sintered at $1450{ }^{\circ} \mathrm{C}$ for $3 \mathrm{~h}$ in $\mathrm{N}_{2}$, air, and $\mathrm{O}_{2}$ with a heating rate of $3{ }^{\circ} \mathrm{C} \cdot \mathrm{min}^{-1}$ and a cooling rate of $5{ }^{\circ} \mathrm{C} \cdot \mathrm{min}^{-1}$, which were abbreviated as $0.25 \mathrm{Mn}-\mathrm{N}, 0.25 \mathrm{Mn}-\mathrm{A}$, and $0.25 \mathrm{Mn}-\mathrm{O}$, respectively. And the pure BCZT specimens were sintered at $1500{ }^{\circ} \mathrm{C}$ for $3 \mathrm{~h}$ in $\mathrm{N}_{2}$, air, and $\mathrm{O}_{2}$, which were abbreviated as $0 \mathrm{Mn}-\mathrm{N}, 0 \mathrm{Mn}-\mathrm{A}$, and $0 \mathrm{Mn}-\mathrm{O}$, respectively. For electric measurement, the two main surfaces of the sintered disk samples were coated with silver paste and then heat-treated at $550{ }^{\circ} \mathrm{C}$ for $30 \mathrm{~min}$. The disk samples were poled in silicon oil under a direct current electric field of $3 \mathrm{kV} \cdot \mathrm{mm}^{-1}$ at $40{ }^{\circ} \mathrm{C}$ for $35 \mathrm{~min}$.

After mechanical polishing and thermally etching at $1400{ }^{\circ} \mathrm{C}$ for $0.5 \mathrm{~h}$, the microstructure of the sintered ceramics was measured using the scanning electron microscopy (SEM; Gemini 300, Zeiss, Germany). The density of the specimens was measured using the Archimedes method in distilled water. Crystalline structure of the ceramics was determined by X-ray diffraction (XRD; Rigaku 2500, Japan) using $\mathrm{Cu} \mathrm{K \alpha}$ radiation with a monochromator. High-resolution X-ray photoelectron spectroscopy (XPS) data of the crushed sintered ceramics were obtained using an ESCALab 250 Xi electron spectrometer (Thermo Fisher Scientific, USA). Crystal structure and lattice parameters of samples were analyzed using Rietveld refinements with GSAS software. Raman spectrum in the range from 100 to $1000 \mathrm{~cm}^{-1}$ was measured using $632 \mathrm{~nm}$ radiation by a Raman microscope spectrometer (LabRAM HR Evolution, Horiba, France). The quasistatic piezoelectric coefficient $\left(d_{33}\right)$ of the poled ceramics was measured using a quasistatic $d_{33}$ meter (ZJ-3A, Institute of Acoustics, Chinese Academy of Sciences, Beijing, China). Permittivity $\left(\varepsilon_{33}^{T}\right)$ and dielectric $\operatorname{loss}(\tan \delta)$ at $1 \mathrm{kHz}$ were measured using a capacitance meter (Agilent 4294A, Agilent, Santa Clara, USA). The planar electro-mechanical coupling factor $\left(k_{\mathrm{p}}\right)$ was determined by an impedance analyzer (Agilent 4294A, Agilent, Santa Clara, USA). The temperature-dependent dielectric properties were measured from -50 to $200{ }^{\circ} \mathrm{C}$ (Agilent 4980A, Agilent, Santa Clara, USA). The ferroelectric polarization hysteresis $(P-E)$ loops and electric field- 
strain $(S-E)$ curves were obtained by the TF Analyzer 3000 ferroelectric measuring system (aixACCT Systems $\mathrm{GmbH}$, Aachen, Germany).

\section{Results and discussion}

\section{1 Phase structure analysis}

Figure 1 exhibits the SEM images of thermally etched surface of all ceramic samples. As can be seen, all ceramic samples have a dense microstructure, with a high relative density (above 97\%, summarized in Table 1), which is responsible for the excellent electrical properties [22]. In addition, different sintering atmospheres have no obvious effect on grain size. However, with the introduction of $\mathrm{Mn}$, the grain size decreases from $\sim 20$ to $\sim 10 \mu \mathrm{m}$, because the doping Mn could inhibit grain growth [23]. Therefore, the percentage of non-ferroelectric grain boundaries is higher in Mn-doped ceramics, which would degrade the piezoelectric properties.

Figure 2(a) exhibits the XRD patterns of the sintered

Table 1 Electrical properties of the BCZT ceramics sintered in different atmospheres

\begin{tabular}{ccccccc}
\hline Sample & $\begin{array}{c}d_{33} \\
\left(\mathrm{pC} \cdot \mathrm{N}^{-1}\right)\end{array}$ & $\begin{array}{c}k_{\mathrm{p}} \\
(\%)\end{array}$ & $\tan \delta$ & $\varepsilon_{33}^{T}$ & $\begin{array}{c}d_{33}^{*} \\
\left(\mathrm{pm} \cdot \mathrm{V}^{-1}\right)\end{array}$ & $\begin{array}{c}\text { Relative } \\
\text { intensity }\end{array}$ \\
\hline 0Mn-N & 483 & 49 & 0.018 & 4054 & 382 & $97.0 \%$ \\
$0 \mathrm{Mn}-\mathrm{A}$ & 540 & 52 & 0.018 & 4338 & 397 & $97.2 \%$ \\
$0 \mathrm{Mn}-\mathrm{O}$ & 585 & 56 & 0.014 & 4621 & 412 & $97.5 \%$ \\
$0.25 \mathrm{Mn}-\mathrm{N}$ & 505 & 50 & 0.013 & 4261 & 345 & $97.2 \%$ \\
$0.25 \mathrm{Mn}-\mathrm{A}$ & 458 & 45 & 0.014 & 3893 & 325 & $97.3 \%$ \\
$0.25 \mathrm{Mn}-\mathrm{O}$ & 432 & 43 & 0.015 & 3880 & 315 & $97.1 \%$ \\
\hline
\end{tabular}

BCZT ceramics at room temperature. No secondary phase could be observed in all samples, which indicates that all doping elements $(\mathrm{Ca}, \mathrm{Zr}$, and $\mathrm{Mn})$ are completely diffused into the $\mathrm{BaTiO}_{3}$ lattice. In addition, all the samples sintered under different atmospheres have a similar expanded XRD pattern ranging from $44.9^{\circ}$ to $45.7^{\circ}$, which demonstrates that the sintering atmosphere has almost no effect on the phase structure. Generally, the diffraction peaks around $45^{\circ}$ are indexed as (200) of rhombohedral phase, $(022) /(200)$ of orthorhombic phase, or $(200) /(002)$ of tetragonal phase. The multiple peaks, around $45^{\circ}$ indicate the coexistence of rhombohedral, orthorhombic, and tetragonal phases in the BCZT ceramics. It is also verified by XRD Rietveld refinement in the following section.

The XRD patterns are Rietveld refined on an assistance of GSAS software as shown in Fig. 3 and the content of each phase structure is shown in the inset. Table 2 lists the refined parameters of the BCZT ceramics. And the $R_{\mathrm{wp}}$ value and $R_{\mathrm{p}}$ value are far less than $15 \%$, which demonstrates that the Rietveld refinement results are reliable. The Rietveld refinement confirms the coexistence of rhombohedral, orthorhombic, and tetragonal phases. The slight different phase structure content and lattice parameters can be induced by the local structural disorder due to the Mn-doping and different sintering atmospheres [24]. The site occupancies are summarized in Table $\mathrm{S} 1$ in the Electronic Supplementary Material (ESM). Additionally, the ion coordination number $(\mathrm{CN})$ and ion radius are shown in Table S2 in the ESM. The Rietveld refinement results demonstrate $\mathrm{Mn}$ ions prefer to enter the B site.
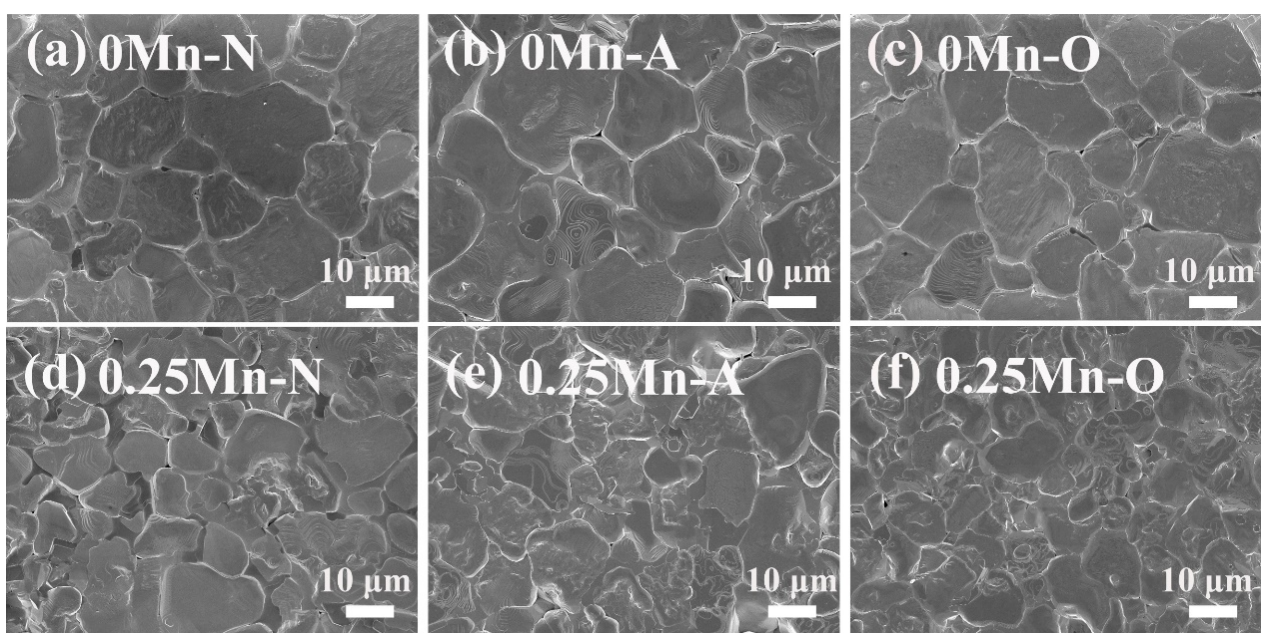

Fig. 1 SEM micrographs of the thermally etched surface of BCTZ ceramics: (a) $0 \mathrm{Mn}-\mathrm{N}$, (b) 0Mn-A, (c) $0 \mathrm{Mn}-\mathrm{O}$, (d) $0.25 \mathrm{Mn}-\mathrm{N}$, (e) $0.25 \mathrm{Mn}-\mathrm{A}$, and (f) $0.25 \mathrm{Mn}-\mathrm{O}$. 


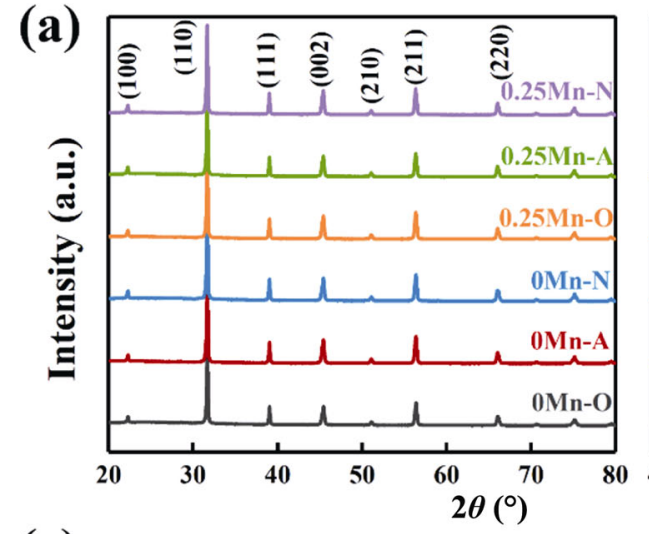

(c)

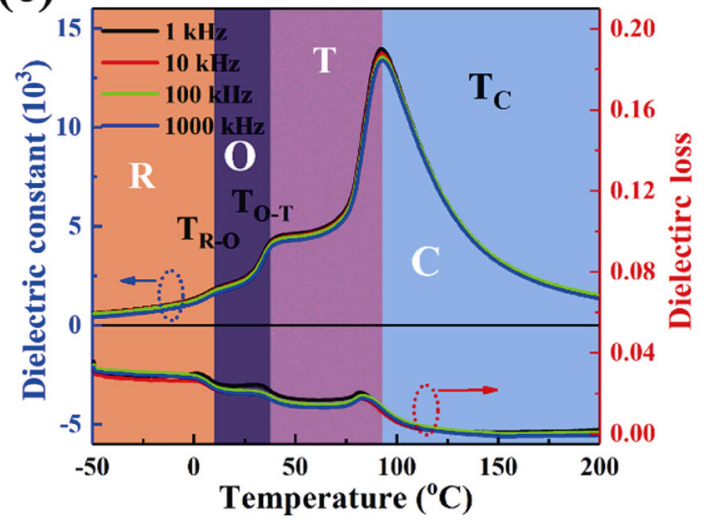

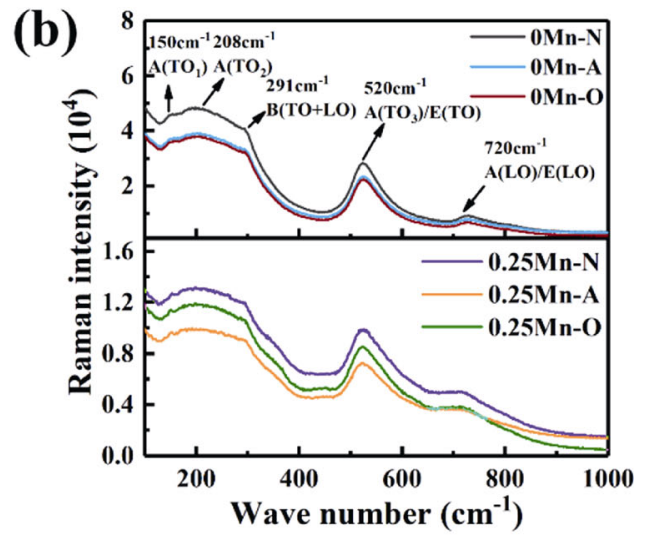

(d)

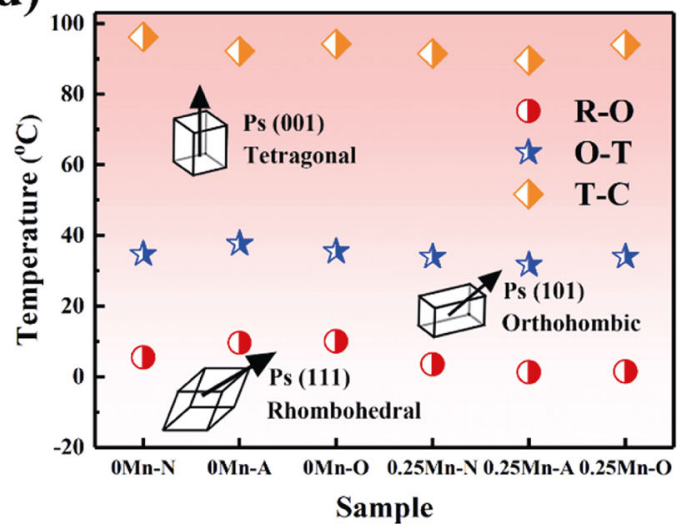

Fig. 2 (a) XRD patterns of the BCZT ceramics in the $2 \theta$ range of $20^{\circ}-80^{\circ}$ and $44.9^{\circ}-45.7^{\circ}$, (b) room-temperature Raman spectra of the BCZT ceramics, (c) dielectric constant and loss of 0Mn-A sample as a function of temperature, and (d) phase transition temperatures of the BCZT ceramics.
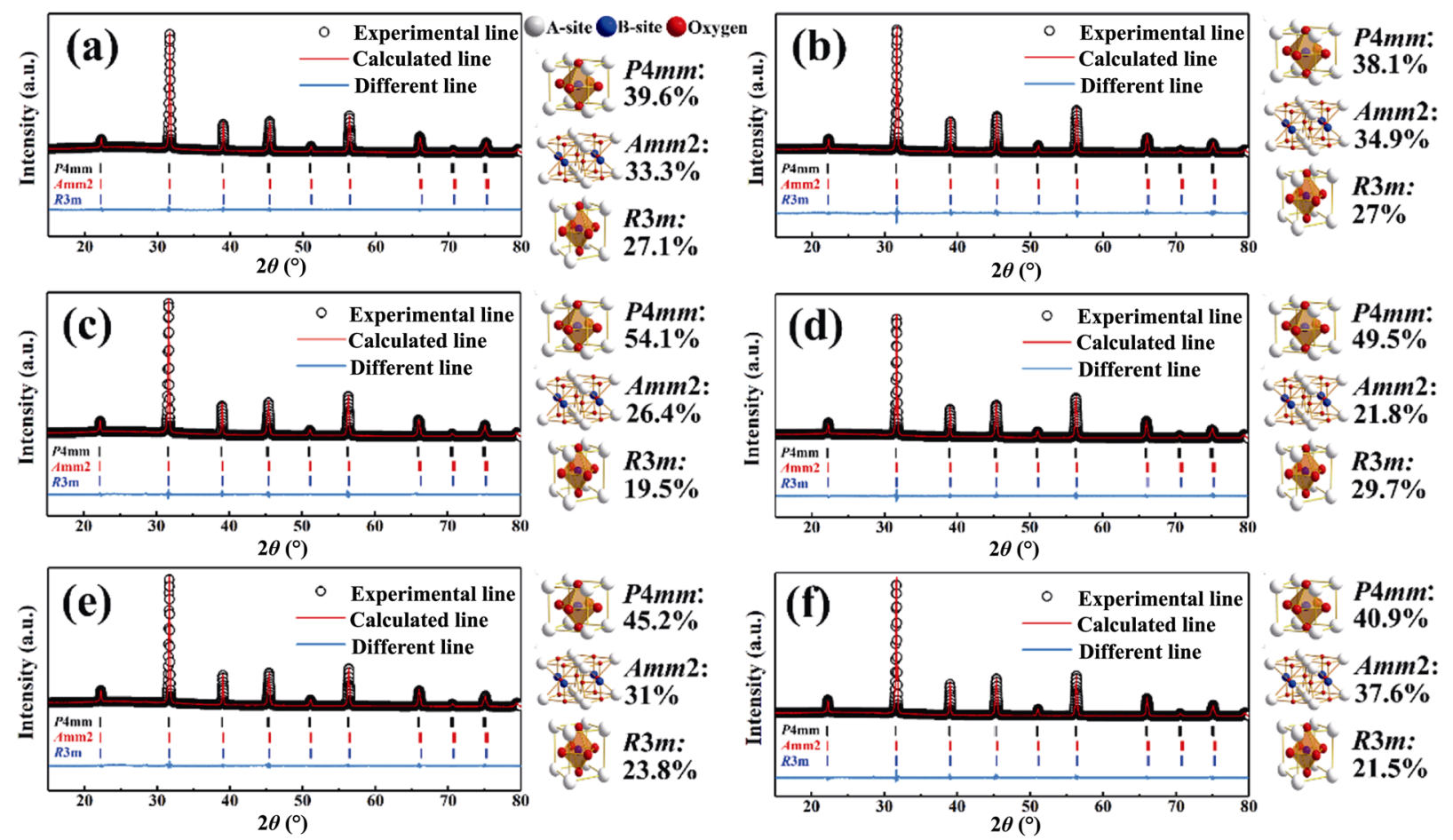

Fig. 3 XRD patterns and Rietveld refinement results of BCZT ceramics: (a) 0Mn-N, (b) 0Mn-A, (c) 0Mn-O, (d) 0.25Mn-O, (e) $0.25 \mathrm{Mn}-\mathrm{A}$, and (f) $0.25 \mathrm{Mn}-\mathrm{O}$. 
Table 2 Lattice parameters and refinement parameters of BCZT ceramics obtained from XRD Rietveld refinement

\begin{tabular}{|c|c|c|c|c|c|c|c|}
\hline Sample & Space group & $a(\AA)$ & $b(\AA)$ & $c(\AA)$ & $\alpha\left(^{\circ}\right)$ & $R_{\mathrm{wp}}(\%)$ & $R_{\mathrm{p}}(\%)$ \\
\hline & $P 4 m m$ & 3.9989 & 3.9989 & 4.0060 & 90 & & \\
\hline \multirow[t]{3}{*}{$0 \mathrm{Mn}-\mathrm{N}$} & $A m m 2$ & 4.0088 & 5.6413 & 5.6477 & 90 & 7.76 & 5.29 \\
\hline & $R 3 m$ & 4.0047 & 4.0047 & 4.0047 & 90.1206 & & \\
\hline & $P 4 m m$ & 3.9951 & 3.9951 & 4.0063 & 90 & & \\
\hline \multirow[t]{3}{*}{ 0Mn-A } & $A m m 2$ & 3.9916 & 5.6558 & 5.6527 & 90 & 7.60 & 5.15 \\
\hline & $R 3 m$ & 3.9981 & 3.9981 & 3.9981 & 90.0059 & & \\
\hline & $P 4 m m$ & 3.9799 & 3.9799 & 4.0070 & 90 & & \\
\hline \multirow[t]{3}{*}{$0 \mathrm{Mn}-\mathrm{O}$} & Amm 2 & 3.9915 & 5.6587 & 5.6495 & 90 & 5.82 & 4.35 \\
\hline & $R 3 m$ & 4.0064 & 4.0064 & 4.0064 & 89.9483 & & \\
\hline & $P 4 m m$ & 3.9799 & 3.9799 & 4.0070 & 90 & & \\
\hline \multirow[t]{3}{*}{$0.25 \mathrm{Mn}-\mathrm{N}$} & $A m m 2$ & 3.9908 & 5.6598 & 5.6561 & 90 & 6.81 & 5.00 \\
\hline & $R 3 m$ & 4.0084 & 4.0084 & 4.0084 & 89.7982 & & \\
\hline & $P 4 m m$ & 3.9919 & 3.9919 & 3.9980 & 90 & & \\
\hline \multirow[t]{3}{*}{$0.25 \mathrm{Mn}-\mathrm{A}$} & $A m m 2$ & 3.9919 & 5.6620 & 5.6763 & 90 & 5.99 & 4.52 \\
\hline & $R 3 m$ & 3.9977 & 3.9977 & 3.9977 & 90.1750 & & \\
\hline & $P 4 m m$ & 3.9909 & 3.9909 & 3.9990 & 90 & & \\
\hline \multirow[t]{2}{*}{$0.25 \mathrm{Mn}-\mathrm{O}$} & $A m m 2$ & 3.9993 & 5.6664 & 5.6730 & 90 & 6.09 & 4.48 \\
\hline & $R 3 m$ & 4.0043 & 4.0043 & 4.0043 & 89.8550 & & \\
\hline
\end{tabular}

Raman spectroscopy is often used to investigate the crystal structure of perovskite ceramics. Figure 2(b) presents the room temperature Raman spectra of BCZT-based ceramics in the frequency range $100-1000 \mathrm{~cm}^{-1}$. Five Raman bands of $\mathrm{A}\left(\mathrm{TO}_{1}\right)$, A $\left(\mathrm{TO}_{2}\right), \mathrm{B}(\mathrm{TO}+\mathrm{LO}), \mathrm{A}\left(\mathrm{TO}_{3}\right) / \mathrm{E}(\mathrm{TO})$, and $\mathrm{A}(\mathrm{LO}) / \mathrm{E}$ (LO) at 150, 208, 291, 520, and $720 \mathrm{~cm}^{-1}$, respectively, are observed. The low wavenumber band is assigned to the vibration within the A-site of the perovskite, whereas the high wavenumber bands could be assigned to the vibrations of the $\mathrm{TiO}_{6}$ octahedra [25]. The main feature of Raman spectra is consistent with tetragonal phase such as the extremely sharp and strong mode at $720 \mathrm{~cm}^{-1}$ [26]. The peak mode near $191 \mathrm{~cm}^{-1}$ exists in the rhombohedral and orthorhombic phases [27,28]. The mode around $208 \mathrm{~cm}^{-1}$ is the characteristic phonon mode of orthorhombic $\mathrm{BaTiO}_{3}$, and the peak at $291 \mathrm{~cm}^{-1}$ confirms the coexistence of the rhombohedral and tetragonal phases $[29,30]$. Therefore, the rhombohedral, tetragonal, and orthorhombic phases coexist in the BCZT ceramics. In the Mn-doped BCZT ceramics, the phonon modes of $\mathrm{A}, \mathrm{B}$, and $\mathrm{E}$ widen, and their peak positions are slightly shifted. It should attribute to the different atomic mass between the Mn-doping element and the pristine $\mathrm{Ti} / \mathrm{Zr}$ elements at the $\mathrm{B}$ site. Besides, the Raman intensity of the pure BCZT ceramics is much higher than that of the Mn-doped BCZT ceramics.
$\mathrm{Ti}^{4+} / \mathrm{Zr}^{4+}$ ions have a high polarizability at the B site of perovskite ceramics. The replacement of $\mathrm{Ti}^{4+} / \mathrm{Zr}^{4+}$ by $\mathrm{Mn}$ ions weakens the dipole moment of the ceramics. It leads to a decrease in the polarizability of the unit cell, which is responsible for the decreasing Raman intensity. The higher polarizability in the pure BCZT ceramics should result in the better ferroelectric, dielectric, and piezoelectric properties [31].

To further discuss the phase structure of ceramics, the temperature dependence of dielectric constant and dielectric loss at $1,10,100$, and $1000 \mathrm{kHz}$ is measured in Fig. 2(c) and Fig. S1 in the ESM. Figure 2(d) summarizes the phase transition temperature of all samples. It can be found that the sintering atmosphere has almost no effect on the phase transition temperature. Combined with the XRD and Raman results, it can prove the coexistence of rhombohedral, orthorhombic, and tetragonal phases at room temperature. MPB is constructed at room temperature, which could essentially enhance the piezoelectric performance of BCZT ceramics. Also, the corresponding dielectric loss peak appears at every phase transition temperature. After doping the Mn element, the rhombohedral-orthorhombic transition temperature slightly decreases. Meanwhile, the dielectric loss reduces. The lower dielectric loss is due to the "hardening effect" as the introduction of acceptor Mn element [22,32]. 
The element composition and valence distribution of the samples are explored by high-resolution XPS spectra. The binding energy centered at $\sim 777.43, \sim 346.15$, $\sim 457.05$, and $\sim 178.7 \mathrm{eV}$ correspond to $\mathrm{Ba} 3 \mathrm{~d}, \mathrm{Ca} 2 \mathrm{p}, \mathrm{Ti}$ $2 \mathrm{p}$, and $\mathrm{Zr} 3 \mathrm{~d}$, respectively. Besides, these elements in different samples have nearly the same binding energies, which indicates that the sintering atmosphere has almost no effect on the valance states of the above elements as displayed in Fig. S2 in the ESM.

\section{2 Defect structure analysis of undoped ceramics}

To explore the influence of defect structure on electrical properties, the impedance spectroscopy and Hall measurement are performed on the sample as shown in Fig. 4. Figure 4(a) plots the Hall voltage $\left(V_{\mathrm{H}}\right)$ as a function of the applied magnetic field. Hall resistance, carrier type, and concentration are summarized in Table 3 [33]. The results illustrate that the pure BCZT ceramics sintered in all atmospheres exhibit an n-type electron conduction mechanism, which means that the free electron primarily affects the conductivity. The Hall resistance of $0 \mathrm{Mn}-\mathrm{N}, 0 \mathrm{Mn}-\mathrm{A}$, and $0 \mathrm{Mn}-\mathrm{O}$ are $1.54 \times 10^{7}, 2.4 \times 10^{7}$, and $4.38 \times 10^{7} \Omega \cdot \mathrm{cm}$, respectively.
The carrier concentration $(c)$ could be calculated as follows [34]:

$$
c=\frac{1}{e \times \frac{V_{\mathrm{H}} d}{I B}}
$$

where $B, I, e$, and $d$ represent the magnetic field, current, electronic charge, and thickness of the bulk ceramic, respectively. The electron concentrations of $0 \mathrm{Mn}-\mathrm{N}, 0 \mathrm{Mn}-\mathrm{A}$, and $0 \mathrm{Mn}-\mathrm{O}$ are $4.22 \times 10^{7}, 2.05 \times 10^{7}$, and $1.28 \times 10^{7} \mathrm{~cm}^{-3}$, respectively. The results indicate that the undoped ceramics sintered at high oxygen partial pressure have higher resistance and lower charge carrier density.

Figure 4(b) shows the impedance spectra of $0 \mathrm{Mn}-\mathrm{O}$ ceramics measured at $600{ }^{\circ} \mathrm{C}$ under pure nitrogen $\left(P_{\mathrm{O}_{2}} \approx\right.$ $\left.10^{-5} \mathrm{~atm}\right)$, air $\left(P_{\mathrm{O}_{2}} \approx 0.2 \mathrm{~atm}\right)$, and pure oxygen $\left(P_{\mathrm{O}_{2}} \approx\right.$ $1 \mathrm{~atm}$. It can be seen from the Nyquist diagram that there are no spikes and arcs associated with Warburg diffusion and oxygen ion conduction. This indicates that the electron carrier is mainly responsible for the conductivity response $[35,36]$. The radius of $Z^{*}$ semicircle increases in the order of $\mathrm{N}_{2}$, air, and $\mathrm{O}_{2}$. It indicates that the resistance of $0 \mathrm{Mn}-\mathrm{O}$ ceramic gradually
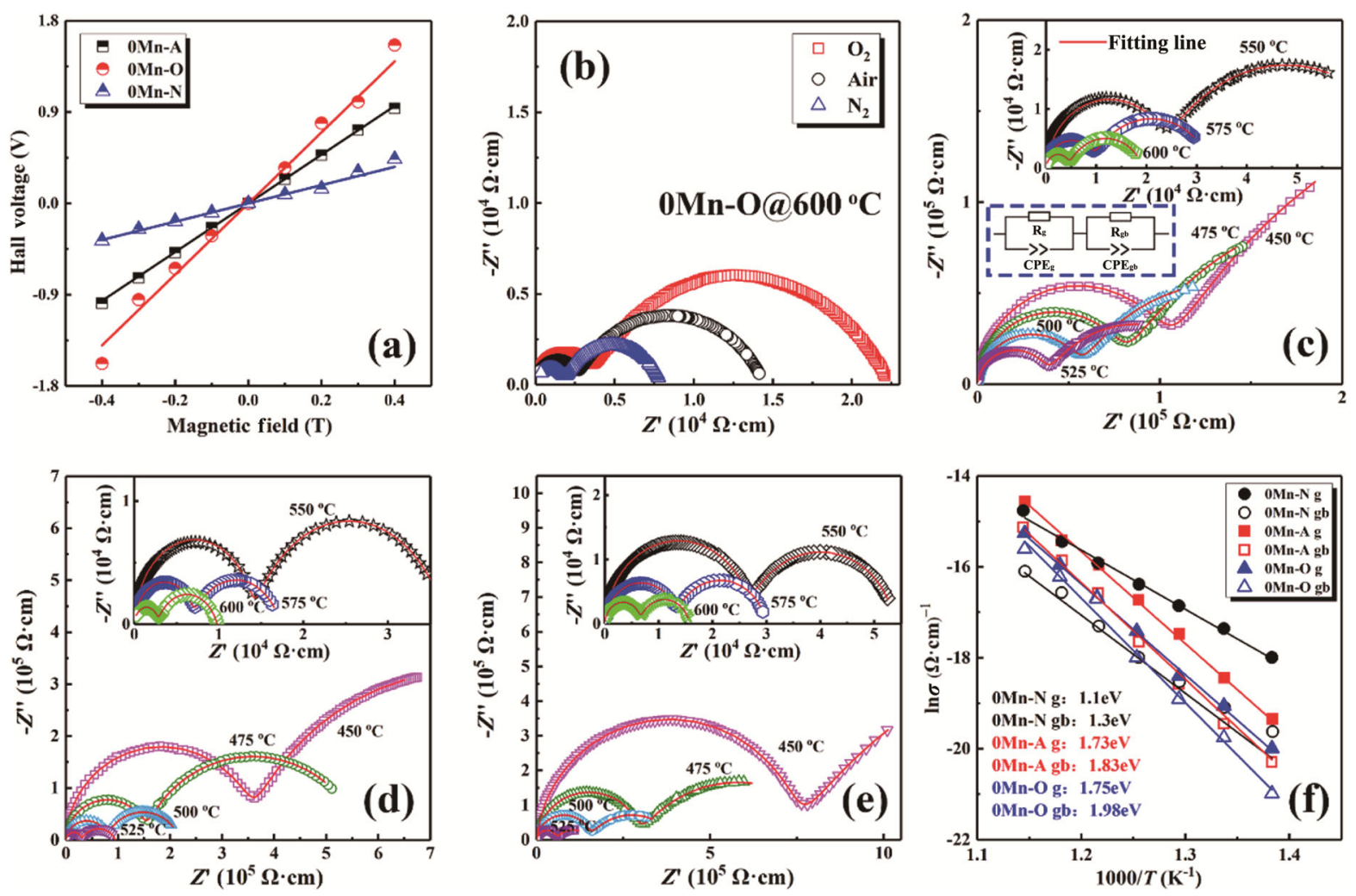

Fig. 4 (a) Voltage as a function of applied magnetic field (0Mn-N, 0Mn-A, 0Mn-O); (b) impedance spectrum of 0Mn-O measured at $600{ }^{\circ} \mathrm{C}$ in nitrogen, air, and oxygen; impedance spectra of (c) $0 \mathrm{Mn}-\mathrm{N}$, (d) 0Mn-A, and (e) $0 \mathrm{Mn}-\mathrm{O}$ measured at 450-600 ${ }^{\circ} \mathrm{C}$ in air, respectively; and (f) Arrhenius plots and the fitted $E_{\mathrm{a}}$ values of $0 \mathrm{Mn}-\mathrm{N}, 0 \mathrm{Mn}-\mathrm{A}$, and $0 \mathrm{Mn}-\mathrm{O}$. 
Table 3 Carrier type, carrier concentration, and Hall resistivity of the $B C Z T$ ceramics sintered in different atmospheres

\begin{tabular}{cccc}
\hline Sample & Carrier type & Concentration $\left(\mathrm{cm}^{-3}\right)$ & Hall resistivity $(\Omega \cdot \mathrm{cm})$ \\
\hline $0 \mathrm{Mn}-\mathrm{N}$ & $\mathrm{n}$ & $4.22 \times 10^{7}$ & $1.54 \times 10^{7}$ \\
$0 \mathrm{Mn}-\mathrm{A}$ & $\mathrm{n}$ & $2.05 \times 10^{7}$ & $2.40 \times 10^{7}$ \\
$0 \mathrm{Mn}-\mathrm{O}$ & $\mathrm{n}$ & $1.28 \times 10^{7}$ & $4.38 \times 10^{7}$ \\
$0.25 \mathrm{Mn}-\mathrm{N}$ & $\mathrm{p}$ & $1.05 \times 10^{8}$ & $1.28 \times 10^{7}$ \\
$0.25 \mathrm{Mn}-\mathrm{A}$ & $\mathrm{p}$ & $2.28 \times 10^{8}$ & $1.04 \times 10^{7}$ \\
$0.25 \mathrm{Mn}-\mathrm{O}$ & $\mathrm{p}$ & $3.59 \times 10^{8}$ & $5.50 \times 10^{6}$ \\
\hline
\end{tabular}

increases with the increase of ambient oxygen partial pressure, in accordance with the Hall results.

Figures 4(c)-4(e) summarize the impedance spectra measured in air at $450-600{ }^{\circ} \mathrm{C}$ for the pure BCZT ceramics sintered under different atmospheres. The Nyquist spectra consist of arcs caused by two different electrically active regions, with the left semicircle at high frequency representing a function of grain effect and the right semicircle representing a function of grain boundary effect. To obtain the resistance of grain $\left(R_{\mathrm{g}}\right)$ and grain boundary $\left(R_{\mathrm{gb}}\right)$, and the capacitance of grain $\left(\mathrm{CPE}_{\mathrm{g}}\right)$ and grain boundary $\left(\mathrm{CPE}_{\mathrm{gb}}\right)$, the Nyquist plots are fitted with the assumed equivalent circuit in the inset of Fig. 4(c) on an assistance of Z-view software. The fitting data (red lines) coincides well with the experimental curves. The conductivities $\left(\sigma_{\mathrm{g}}\right.$ and $\left.\sigma_{\mathrm{gb}}\right)$ of grain and grain boundary are calculated by $\sigma=1 / \rho=$ $t /(R S)$ (where $\sigma$ represents the conductivity of the sample, $\rho$ is the resistivity, $t$ is the thickness of the sample, $R$ is the resistance, and $S$ is the area of the sample). $\ln \sigma$ is linearly associated with $T^{-1}$ as displayed in Fig. 4(f), demonstrating that the Arrhenius law commonly governs the conductivity. The activation energy $\left(E_{\mathrm{a}}\right)$ of the grains and grain boundary could be calculated as follows:

$$
\sigma=\sigma_{0} \exp \left(\frac{-E_{\mathrm{a}}}{k_{\mathrm{B}} T}\right)
$$

where $\sigma_{0}$ is the high-temperature limit of the conductivity, $E_{\mathrm{a}}$ is the activation energy, $k_{\mathrm{B}}$ is the Boltzmann constant, and $T$ is the temperature in Kelvin scale. The calculated $E_{\mathrm{a}}$ values are shown in Fig. 4(f). The $E_{\mathrm{a}}$ of the grains are 1.1, 1.73, and $1.75 \mathrm{eV}$, while $E_{\mathrm{a}}$ of grain boundaries are $1.3,1.83$, and $1.98 \mathrm{eV}$, for OMn-N, 0Mn-A, and 0Mn-O samples, respectively. The activation energy expresses the free energy required for the long-range carrier leap. The lower $E_{\mathrm{a}}$ in the $0 \mathrm{Mn}-\mathrm{N}$ ceramics declare that the free electrons in the ceramics have higher mobility, generating to a significant weakening of the insulating properties.

When the undoped BCZT ceramics are sintered at high temperature, the oxygen ions in the crystal lattice could become oxygen accompanied by the formation of an ionized oxygen vacancy $\left(\mathrm{V}_{\mathrm{O}}^{*}\right)$ and two electrons $\left(\mathrm{e}^{\prime}\right)$, which can be expressed as Eq. (3) [37]:

$$
\mathrm{O}_{\mathrm{O}}^{\times} \leftrightarrow \frac{1}{2} \mathrm{O}_{2} \uparrow+\mathrm{V}_{\mathrm{O}}^{\ddot{*}}+2 \mathrm{e}^{\prime}
$$

Therefore, the defects of electrons and oxygen vacancies mainly exist in undoped BCZT ceramics. Since the mobility of the charged oxygen vacancy is significantly weaker than that of the electron, the conduction of the sample should be attributed mainly to the free electron. When the samples are sintered in low oxygen partial pressure, Reaction (3) shifts to the right, resulting in a rapid increase of electrons. Therefore, the defect configurations of the pure BCZT ceramics sintered in different atmospheres are sketched in Figs. 5(a)-5(c). As the oxygen partial pressure decreases, the number of oxygen vacancies and free electrons gradually increases. Therefore, the pure BCZT ceramics sintered in high oxygen partial pressure tend to have the higher insulation resistivity.

\section{3 Defect structure analysis of Mn-doped BCZT ceramics}

Figure 6 shows the Mn 2p XPS spectra fitted by Gaussian-Lorenz function. Three fitting peaks from low binding energy to high binding energy correspond to $\mathrm{Mn}^{2+}$ (located at $640.5 \mathrm{eV}$ ), $\mathrm{Mn}^{3+}$ (located at $641.3 \mathrm{eV}$ ), and $\mathrm{Mn}^{4+}$ (located at $642.1 \mathrm{eV}$ ). The content of different

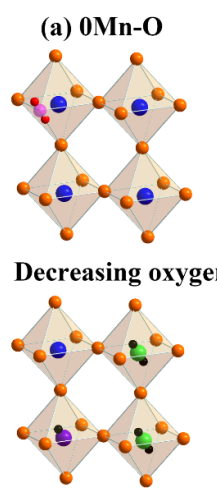

(d) $0.25 \mathrm{Mn}-\mathrm{O}$

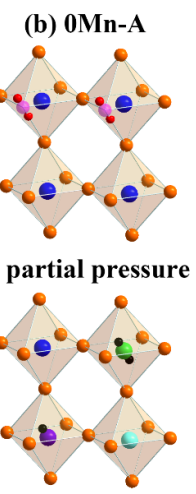

(e) $0.25 \mathrm{Mn}-\mathrm{A}$

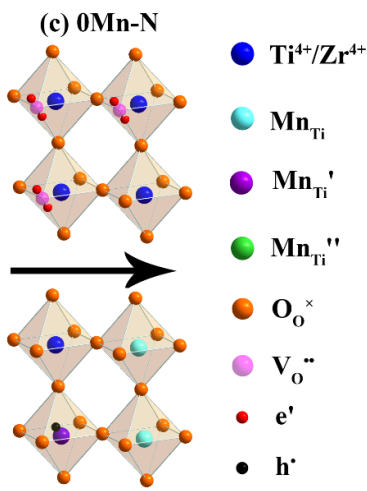

(f) $0.25 \mathrm{Mn}-\mathrm{N}$
Fig. 5 Schematic diagrams of defect configuration for BCZT-based ceramics. 


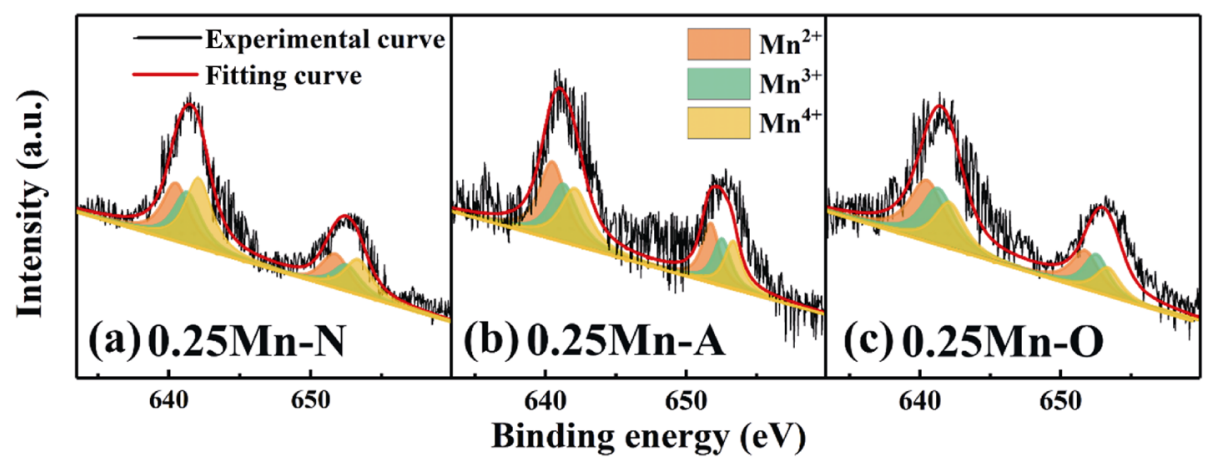

Fig. 6 High-resolution Mn 2p spectra and the corresponding fitting curves of (a) $0.25 \mathrm{Mn}-\mathrm{N}$, (b) $0.25 \mathrm{Mn}-\mathrm{A}$, and (c) $0.25 \mathrm{Mn}-\mathrm{O}$.

Mn elements is shown in Table S3 in the ESM. Compared with other components, the proportion of $\mathrm{Mn}^{2+}$ and $\mathrm{Mn}^{3+}$ ions in the Mn-doped ceramics sintered in the low oxygen partial pressure decreases, whereas the proportion of $\mathrm{Mn}^{4+}$ ions increases.

Based on the XPS and XRD analyses, the following defect reactions happened in the Mn-doped BCZT ceramics.

$$
\begin{aligned}
& \mathrm{MnO}_{2} \stackrel{\mathrm{TiO}_{2}}{\longrightarrow} \mathrm{Mn}_{\mathrm{Ti}}+2 \mathrm{O}_{\mathrm{O}}^{\times} \\
& \mathrm{MnO}_{2} \stackrel{\mathrm{TiO}_{2}}{\longrightarrow} \mathrm{Mn}_{\mathrm{Ti}}^{\prime}+\mathrm{O}_{\mathrm{O}}^{\times}+\mathrm{V}_{\mathrm{O}}^{\cdot \bullet}+\mathrm{e}^{\prime} \\
& \mathrm{MnO}_{2} \stackrel{\mathrm{TiO}_{2}}{\longrightarrow} \mathrm{Mn}_{\mathrm{Ti}}^{\prime \prime}+\mathrm{O}_{\mathrm{O}}^{\times}+\mathrm{V}_{\mathrm{O}}^{*}
\end{aligned}
$$

The ionic defects of $\mathrm{Mn}_{\mathrm{Ti}}, \mathrm{Mn}_{\mathrm{Ti}}^{\prime}$, and $\mathrm{Mn}_{\mathrm{Ti}}^{\prime \prime}$ primarily exist in the Mn-doped ceramics. In addition, the $0.25 \mathrm{Mn}-\mathrm{N}$ sample has a high $\mathrm{Mn}^{4+}$ content, while the ion defects of $\mathrm{Mn}^{2+}$ and $\mathrm{Mn}^{3+}$ are dominant in $0.25 \mathrm{Mn}-\mathrm{O}$ sample. These negatively charged point defects of $\mathrm{Mn}^{2+}$ and $\mathrm{Mn}^{3+}$ ions could trap positively charged holes, while the equivalent doping $\mathrm{Mn}^{4+}$ ions are electrically neutral. The defect configurations of Mn-doped BCZT ceramics sintered in different atmospheres are sketched in Figs. 5(d)-5(f). When the oxygen partial pressure decreases during sintering process, the concentration of holes in the ceramics decreases.

The defect configuration of the Mn-doped ceramics is also verified by the Hall effect as presented in Table 3 and Fig. 7(a). All the Mn-doped ceramics exhibit a p-type conduction mechanism, which means the main charge carrier is hole. The Hall resistance of $0.25 \mathrm{Mn}-\mathrm{N}$, $0.25 \mathrm{Mn}-\mathrm{A}$, and $0.25 \mathrm{Mn}-\mathrm{O}$ are $1.28 \times 10^{7}, 1.04 \times 10^{7}$, and $5.5 \times 10^{6} \Omega \cdot \mathrm{cm}$, respectively. The carrier concentration of $0.25 \mathrm{Mn}-\mathrm{N}, 0.25 \mathrm{Mn}-\mathrm{A}$, and $0.25 \mathrm{Mn}-\mathrm{O}$ are $1.05 \times 10^{8}$, $2.28 \times 10^{8}$, and $3.591 \times 10^{8} \mathrm{~cm}^{-3}$, respectively. It indicates that $0.25 \mathrm{Mn}-\mathrm{N}$ has the best insulation performance. Figure 6(b) shows the impedance spectrum of $0.25 \mathrm{Mn}-\mathrm{N}$ at $600{ }^{\circ} \mathrm{C}$ measured in different atmospheres. The semicircle for $0.25 \mathrm{Mn}-\mathrm{N}$ under nitrogen is larger than that under air and oxygen, which implies that the resistance is the highest for $0.25 \mathrm{Mn}-\mathrm{N}$. The Hall and impendence measurements confirm that the Mn-doped ceramics exhibit a p-type conduction mechanism. Therefore, Eq. (7) should exist in the Mn-doped ceramics. When the ceramics are sintered in low oxygen partial pressure, Eq. (7) shifts towards right, leading to the reducing hole concentration.

$$
\mathrm{O}_{\mathrm{O}}^{\times}+2 \mathrm{~h}^{\cdot} \leftrightarrow \mathrm{V}_{\mathrm{O}}^{\ddot{*}}+\frac{1}{2} \mathrm{O}_{2} \uparrow
$$

Figures 7(c)-7(e) summarize the impedance spectra of ceramics sintered under different atmospheres measured at $450-600{ }^{\circ} \mathrm{C}$ in air. The red lines are the fitting results based on an assumed equivalent circuit in the inset of Fig. 7(c). As the oxygen partial pressure of the sintering atmosphere decreases, the semicircle measured at the same temperature derived from the grain and grain boundary contribution gradually increases, implying that ceramics sintered in low oxygen partial pressure have a higher resistance. In addition, the $E_{\mathrm{a}}$ of the grains are $1.45,1.43$, and $1.12 \mathrm{eV}$, while $E_{\mathrm{a}}$ of grain boundaries are $1.62,1.46$, and $1.48 \mathrm{eV}$, for $0.25 \mathrm{Mn}-\mathrm{N}$, $0.25 \mathrm{Mn}-\mathrm{A}$, and $0.25 \mathrm{Mn}-\mathrm{O}$, respectively, as displayed in Fig. 7(f). Hence, the holes are more difficult to jump for $0.25 \mathrm{Mn}-\mathrm{N}$ ceramic because of the higher energy barrier. It implies that the $0.25 \mathrm{Mn}-\mathrm{N}$ ceramic has better insulating properties.

Therefore, the undoped BCZT ceramics exhibit an n-type conduction mechanism and have the lower electron concentration in high oxygen partial pressure. The Mn-doped ceramics show a p-type conduction mechanism and have the lower hole concentration in low oxygen partial pressure. The results confirm that the Mn-doping in small quantity could change drastically the defect configuration for the BCZT ceramics, which would have a great influence on the electrical properties. 

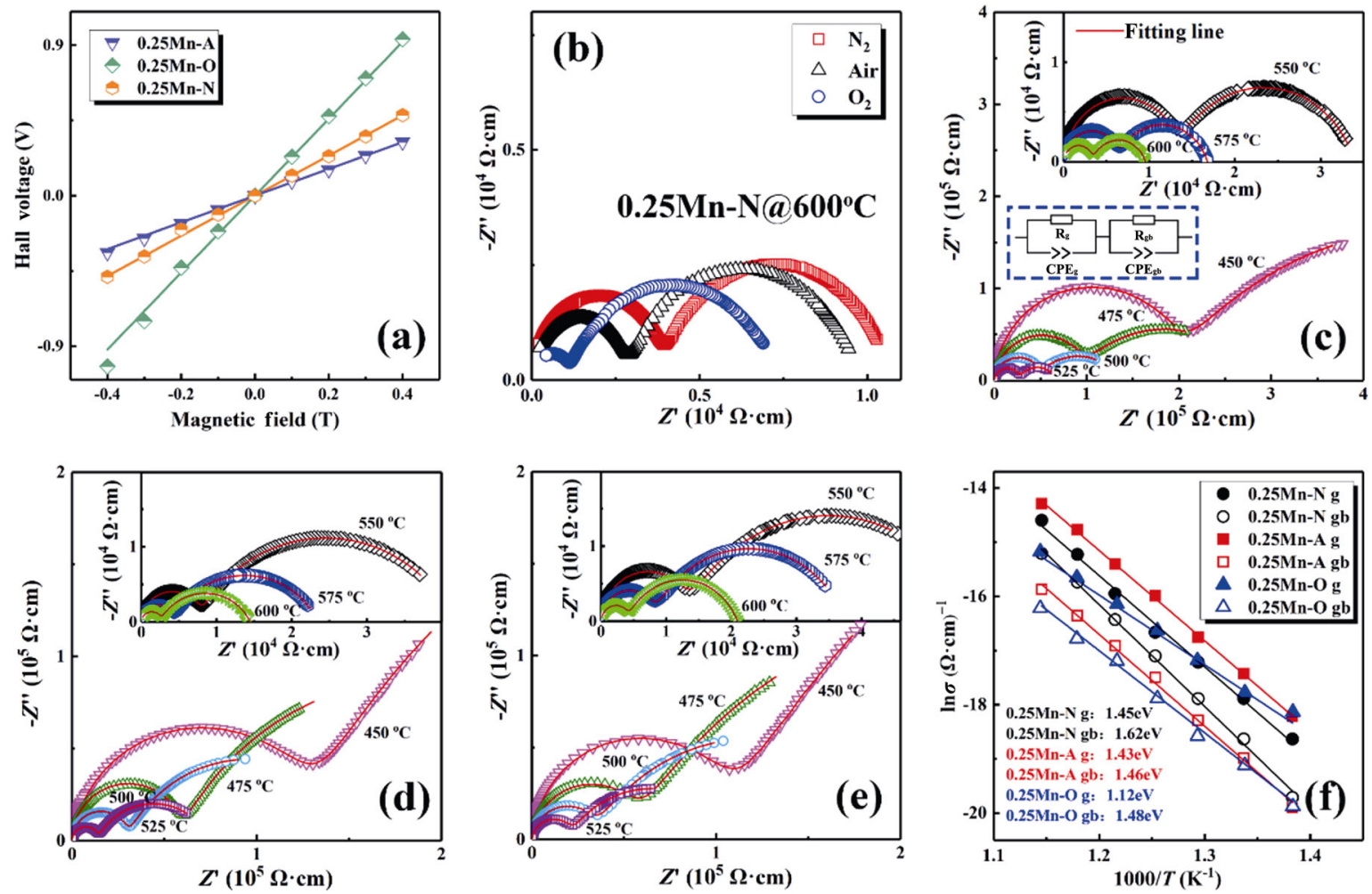

Fig. 7 (a) Voltage as a function of applied magnetic field for $0.25 \mathrm{Mn}-\mathrm{N}, 0.25 \mathrm{Mn}-\mathrm{A}$, and $0.25 \mathrm{Mn}-\mathrm{O}$ samples; (b) impedance spectrum of $0.25 \mathrm{Mn}-\mathrm{N}$ measured at $600{ }^{\circ} \mathrm{C}$ in nitrogen, air, and oxygen; impedance spectra of (c) $0.25 \mathrm{Mn}-\mathrm{N}$, (d) $0.25 \mathrm{Mn}-\mathrm{A}$, and (e) $0.25 \mathrm{Mn}-\mathrm{O}$ at $450-600{ }^{\circ} \mathrm{C}$ in air; and (f) Arrhenius plots and the fitted $E_{\mathrm{a}}$ values of $0.25 \mathrm{Mn}-\mathrm{N}, 0.25 \mathrm{Mn}-\mathrm{A}$, and $0.25 \mathrm{Mn}-\mathrm{O}$.

\section{4 Electrical properties}

Figures 8(a1)-8(a6) show the $P-E$ hysteresis loops and the bipolar $S-E$ curves measured under $40 \mathrm{kV} \cdot \mathrm{cm}^{-1}$ at $1 \mathrm{~Hz}$ for BCZT ceramics sintered under different atmospheres. The maximum polarization $\left(P_{\max }\right)$, remnant polarization $\left(P_{\mathrm{r}}\right)$, and coercive electric field $\left(E_{\mathrm{c}}\right)$ are summarized in Table 4 . The dynamic piezoelectric coefficient $\left(d_{33}^{*}=\right.$ $S_{\max } / E_{\max }$, also known as converse piezoelectric coefficient, where $S_{\max }$ is the max stress-strain and $E_{\max }$ is the max electric field) was calculated by the bipolar $S-E$ curves and summarized in Table 1. The bipolar $S-E$ curves for all ceramic samples show a typical "butterfly" shape, and the Mn-doped ceramics have an asymmetrical structure, indicating the high defect concentration. This is due to the large number of point defects caused by Mn-doping. The electrical properties such as piezoelectrical constant $\left(d_{33}\right)$, electro-mechanical coupling factor $\left(k_{\mathrm{p}}\right)$, dielectric constant $\left(\varepsilon_{33}^{T}\right)$, and dielectric loss $(\tan \delta)$ are summarized in Table $1.0 \mathrm{Mn}-\mathrm{O}$ ceramic samples possess the higher $P_{\max }=18.9 \mu \mathrm{C} \cdot \mathrm{cm}^{-2}$ and $P_{\mathrm{r}}=10.45 \mu \mathrm{C} \cdot \mathrm{cm}^{-2}$ compared with $0 \mathrm{Mn}-\mathrm{N}$ and $0 \mathrm{Mn}-\mathrm{A}$ ceramics. Figures 8(b1)-8(b6) show the unipolar $S-E$ curves measured at $1 \mathrm{~Hz}$ for BCZT ceramics. At room temperature, the dynamic piezoelectric constant of $0 \mathrm{Mn}-\mathrm{O}$ ceramics is $412 \mathrm{pm} \cdot \mathrm{V}^{-1}$ and the unipolar stress-strain reaches $0.165 \%$ at $40 \mathrm{kV} \cdot \mathrm{cm}^{-1}$, indicating the excellent piezoelectric response of $0 \mathrm{Mn}-\mathrm{O}$ ceramics. Furthermore, 0Mn-O achieves the highest $d_{33}=585$ $\mathrm{pC} \cdot \mathrm{N}^{-1}, k_{\mathrm{p}}=56 \%$, and $\varepsilon_{33}^{T}=4621$, which are better than $0 \mathrm{Mn}-\mathrm{A}$ and $0 \mathrm{Mn}-\mathrm{N}$. Additionally, the $\tan \delta$ and $E_{\mathrm{c}}$ decrease when the undoped ceramics are sintered in $\mathrm{O}_{2}$, indicating that $0 \mathrm{Mn}-\mathrm{O}$ ceramics have the lower defect content. Therefore, the undoped ceramics exhibit the highest insulation resistivity and piezoelectric properties.

In the Mn-doped ceramics, $0.25 \mathrm{Mn}-\mathrm{N}$ ceramic sample possesses the higher $P_{\max }=18.5 \mu \mathrm{C} \cdot \mathrm{cm}^{-2}, P_{\mathrm{r}}=9.38$ $\mu \mathrm{C} \cdot \mathrm{cm}^{-2}, d_{33}=505 \mathrm{pC} \cdot \mathrm{N}^{-1}, k_{\mathrm{p}}=50 \%, \varepsilon_{33}^{T}=4261$, and lower $E_{\mathrm{c}}=2.16 \mathrm{kV} \cdot \mathrm{cm}^{-1}$ compared with $0.25 \mathrm{Mn}-\mathrm{O}$ and $0.25 \mathrm{Mn}-\mathrm{A}$ ceramics. Its dynamic piezoelectric constant and unipolar stress-strain reach up to $345 \mathrm{pm} \cdot \mathrm{V}^{-1}$ and $0.136 \%$ at $40 \mathrm{kV} \cdot \mathrm{cm}^{-1}$, respectively. The Mn-doped ceramics sintered in $\mathrm{O}_{2}$ have the higher hole concentration in reference to the Hall and impedance analysis. The large number of point defects pin the domain wall and forbid the domain switching, leading to the lower electrical properties. 

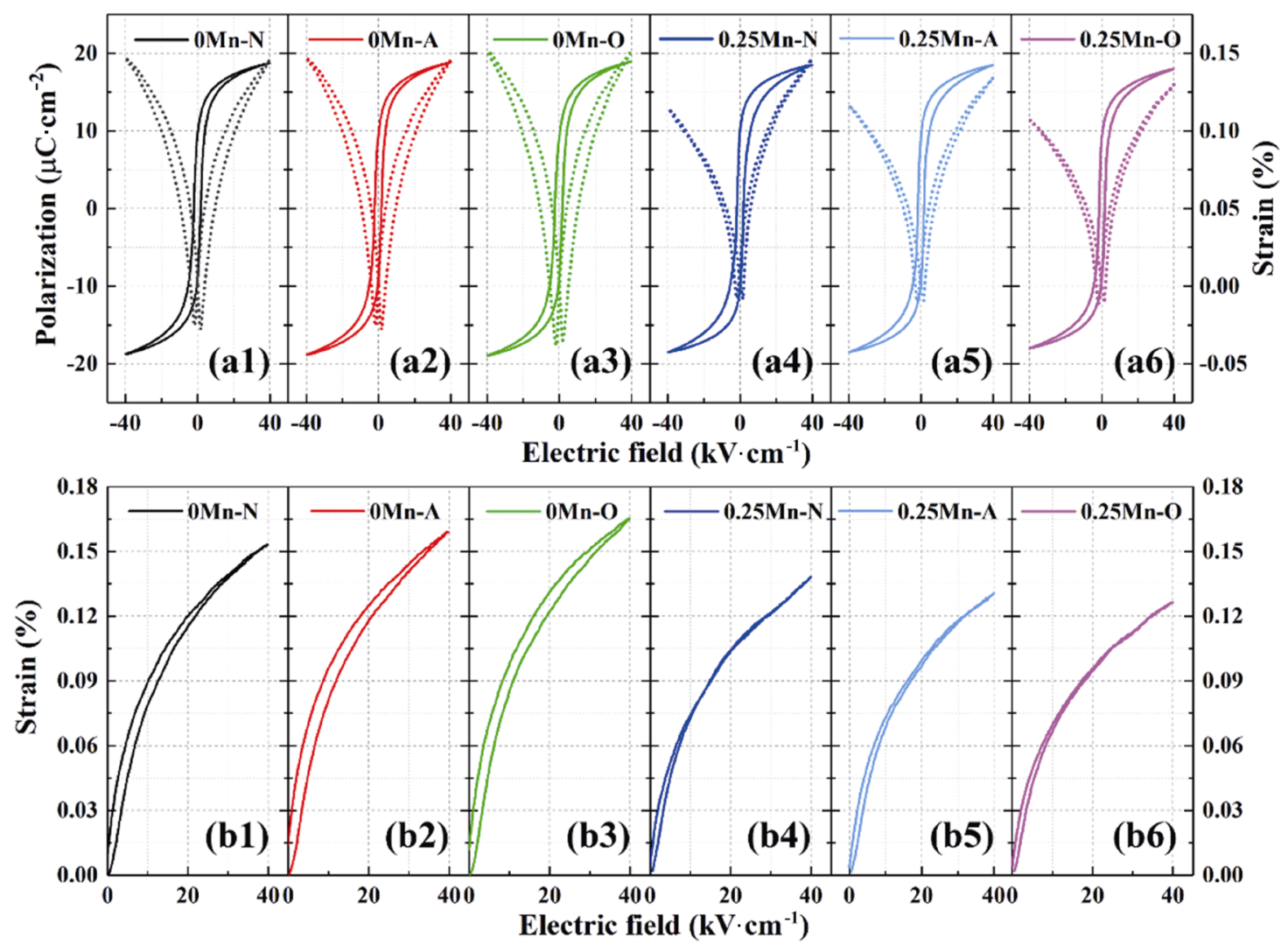

Fig. 8 (a1-a6) $P-E$ hysteresis loops and bipolar $S-E$ curves and (b1-b6) unipolar $S-E$ curves measured at $1 \mathrm{~Hz}$ for BCZT ceramics sintered in different atmospheres.

Table 4 Maximus polarization $\left(P_{\text {max }}\right)$, remnant polarization $\left(P_{\mathrm{r}}\right)$, and coercive electric field $\left(E_{\mathrm{c}}\right)$ obtained from the $P-E$ hysteresis loops

\begin{tabular}{cccc}
\hline & $P_{\max }\left(\mu \mathrm{C} \cdot \mathrm{cm}^{-2}\right)$ & $P_{\mathrm{r}}\left(\mu \mathrm{C} \cdot \mathrm{cm}^{-2}\right)$ & $E_{\mathrm{c}}\left(\mathrm{kV} \cdot \mathrm{cm}^{-1}\right)$ \\
\hline $0 \mathrm{Mn}-\mathrm{N}$ & 18.7 & 9.7 & 1.81 \\
$0 \mathrm{Mn}-\mathrm{A}$ & 18.8 & 10.2 & 1.46 \\
$0 \mathrm{Mn}-\mathrm{O}$ & 18.9 & 10.45 & 1.23 \\
$0.25 \mathrm{Mn}-\mathrm{N}$ & 18.5 & 9.38 & 2.16 \\
$0.25 \mathrm{Mn}-\mathrm{A}$ & 18.45 & 9.29 & 2.26 \\
$0.25 \mathrm{Mn}-\mathrm{O}$ & 18 & 9.02 & 2.15 \\
\hline
\end{tabular}

\section{Conclusions}

The relationship among defect configuration, electrical properties, and sintering atmosphere for the BCZT ceramics was systematically investigated and theoretically analyzed. The Mn-doping element in BCZT ceramics can modulate the intrinsic conduction mechanism and then control the optimal sintering atmospheres. Based on impedance spectroscopy and Hall effect, the undoped ceramics exhibit an n-type conduction mechanism, and the electron concentration for the ceramics sintered under high oxygen partial pressure is minimized. Therefore, the undoped ceramics sintered in $\mathrm{O}_{2}$ have the highest piezoelectric properties $\left(d_{33}=585 \mathrm{pC} \cdot \mathrm{N}^{-1}, k_{\mathrm{p}}=56 \%\right)$. The Mn-doped ceramics exhibit a p-type conduction mechanism, and the hole concentration reduces with the decreasing oxygen partial pressure. The experimental results demonstrate that $0.25 \mathrm{~mol} \% \mathrm{Mn}$-doped ceramics sintered in $\mathrm{N}_{2}$ have the highest piezoelectric properties $\left(d_{33}=505 \mathrm{pC} \cdot \mathrm{N}^{-1}, k_{\mathrm{p}}=50 \%\right)$. This work demonstrates that defect engineering could modulate the intrinsic conduction mechanism and electrical properties. It provides an effective way to predict the optimal sintering atmosphere for the BCZT ceramics.

\section{Acknowledgements}

The work was supported by the National Natural Science Foundation of China (Grant Nos. 52072150 and 51972146), the Young Elite Scientists Sponsorship Program by CAST, the State Key Laboratory of New Ceramics and Fine Processing Tsinghua University (Grant No. KF202002), and the Open Foundation of Guangdong Provincial Key Laboratory of Electronic Functional Materials and Devices (Grant No. EFMD2021002Z). 


\section{Electronic Supplementary Material}

Supplementary material is available in the online version of this article at https://doi.org/10.1007/s40145-021-0526-6.

\section{References}

[1] Tressler J, Alkoy S, Newnham R. Piezoelectric sensors and sensor materials. J Electroceram 1998, 2: 257-272.

[2] Hao JG, Li W, Zhai JW, et al. Progress in high-strain perovskite piezoelectric ceramics. Mater Sci Eng: R: Rep 2019, 135: 1-57.

[3] Gao X, Wu J, Yu Y, et al. Giant piezoelectric coefficients in relaxor piezoelectric ceramic PNN-PZT for vibration energy harvesting. Adv Funct Mater 2018, 28: 1706895.

[4] Jamie RL, Graeme EB, Pedro JJA, et al. Nanomaterials in the environment: Behavior, fate, bioavailability, and effects-An updated review. Environ Toxicol Chem 2018, 37: 2029-2063.

[5] Gao JH, Xue DZ, Liu WF, et al. Recent progress on $\mathrm{BaTiO}_{3}$-based piezoelectric ceramics for actuator applications. Actuators 2017, 6: 24.

[6] Alkathy MS, James Raju KC. Structural, dielectric, electromechanical, piezoelectric, elastic and ferroelectric properties of lanthanum and sodium co-substituted Barium titanate ceramics. $J$ Alloys Compd 2018, 737: 464-476.

[7] Li TY, Lou XJ, Ke XQ, et al. Giant strain with low hysteresis in A-site-deficient $\left(\mathrm{Bi}_{0.5} \mathrm{Na}_{0.5}\right) \mathrm{TiO}_{3}$-based lead-free piezoceramics. Acta Mater 2017, 128: 337-344.

[8] Yin J, Zhao CL, Zhang YX, et al. Ultrahigh strain in site engineering-independent $\mathrm{Bi}_{0.5} \mathrm{Na}_{0.5} \mathrm{TiO}_{3}$-based relaxorferroelectrics. Acta Mater 2018, 147: 70-77.

[9] Wang K, Yao FZ, Koruza J, et al. Electromechanical properties of $\mathrm{CaZrO}_{3}$ modified $(\mathrm{K}, \mathrm{Na}) \mathrm{NbO}_{3}$-based lead-free piezoceramics under uniaxial stress conditions. $\mathrm{J} \mathrm{Am}$ Ceram Soc 2017, 100: 2116-2122.

[10] Li P, Chen XQ, Wang FF, et al. Microscopic insight into electric fatigue resistance and thermally stable piezoelectric properties of $(\mathrm{K}, \mathrm{Na}) \mathrm{NbO}_{3}$-based ceramics. ACS Appl Mater Interfaces 2018, 10: 28772-28779.

[11] Malič B, Koruza J, Hreščak J, et al. Sintering of lead-free piezoelectric sodium potassium niobate ceramics. Materials: Basel 2015, 8: 8117-8146.

[12] Castkova K, Maca K, Cihlar J, et al. Chemical synthesis, sintering and piezoelectric properties of $\mathrm{Ba}_{0.85} \mathrm{Ca}_{0.15} \mathrm{Zr}_{0.1} \mathrm{Ti}_{0.9} \mathrm{O}_{3}$ lead-free ceramics. J Am Ceram Soc 2015, 98: 2373-2380.

[13] Li SB, Wang CB, Li L, et al. Effect of annealing temperature on structural and electrical properties of BCZT ceramics prepared by plasma activated sintering. $J$ Alloys Compd 2018, 730: 182-190.

[14] Coondoo I, Panwar N, Alikin D, et al. A comparative study of structural and electrical properties in lead-free BCZT ceramics: Influence of the synthesis method. Acta Mater 2018, 155: 331-342.
[15] Liu Y, Chang Y, Li F, et al. Exceptionally high piezoelectric coefficient and low strain hysteresis in grain-oriented $(\mathrm{Ba}$, $\mathrm{Ca})(\mathrm{Ti}, \mathrm{Zr}) \mathrm{O}_{3}$ through integrating crystallographic texture and domain engineering. ACS Appl Mater Interfaces 2017, 9: 29863-29871.

[16] Bai WF, Chen DQ, Li P, et al. Enhanced electromechanical properties in <001>-textured $\left(\mathrm{Ba}_{0.85} \mathrm{Ca}_{0.15}\right)\left(\mathrm{Zr}_{0.1} \mathrm{Ti}_{0.9}\right) \mathrm{O}_{3}$ lead-free piezoceramics. Ceram Int 2016, 42: 3429-3436.

[17] Liu W, Ren X. Large piezoelectric effect in Pb-free ceramics. Phys Rev Lett 2009, 103: 257602.

[18] Gao RL, Chu XC, Huan Y, et al. Ceramic-electrode interdiffusion of $(\mathrm{K}, \mathrm{Na}) \mathrm{NbO}_{3}$-based multilayer ceramics with $\mathrm{Ag}_{0.7} \mathrm{Pd}_{0.3}$ electrode. J Eur Ceram Soc 2015, 35: 389-392.

[19] Zhang QW, Cai W, Zhou C, et al. Electric fatigue of BCZT ceramics sintered in different atmospheres. Appl Phys A 2019, 125: 759.

[20] Cai W, Zhang QW, Zhou C, et al. Effects of oxygen partial pressure on the electrical properties and phase transitions in $(\mathrm{Ba}, \mathrm{Ca})(\mathrm{Ti}, \mathrm{Zr}) \mathrm{O}_{3}$ ceramics. $J$ Mater Sci 2020, 55: 9972-9992.

[21] Zhang SW, Zhang HL, Zhang BP, et al. Dielectric and piezoelectric properties of $\left(\mathrm{Ba}_{0.95} \mathrm{Ca}_{0.05}\right)\left(\mathrm{Ti}_{0.88} \mathrm{Zr}_{0.12}\right) \mathrm{O}_{3}$ ceramics sintered in a protective atmosphere. J Eur Ceram Soc 2009, 29: 3235-3242.

[22] Zhang Y, Sun HJ, Chen W. Influence of cobalt and sintering temperature on structure and electrical properties of $\mathrm{BaZr}_{0.05} \mathrm{Ti}_{0.95} \mathrm{O}_{3}$ ceramics. Ceram Int 2015, 41: 8520-8532.

[23] Zhang Y, Sun HJ, Chen W, et al. Modification of the structure and electrical properties of $\mathrm{Ba}_{0.95} \mathrm{Ca}_{0.05} \mathrm{Zr}_{0.1} \mathrm{Ti}_{0.9} \mathrm{O}_{3}$ ceramics by the doping of Mn ions. J Mater Sci: Mater Electron 2015, 26: 10034-10043.

[24] Yan XD, Zheng MP, Gao X, et al. Giant current performance in lead-free piezoelectrics stem from local structural heterogeneity. Acta Mater 2020, 187: 29-40.

[25] Yao ZH, Luo Q, Xu CB, et al. Titanium deficiency in tetragonal-structured $(\mathrm{Ba}, \mathrm{Ca})(\mathrm{Zr}, \mathrm{Ti}) \mathrm{O}_{3}$ piezoelectric ceramics. J Alloys Compd 2017, 712: 406-411.

[26] Wang $\mathrm{H}$, Yuan $\mathrm{H}, \mathrm{Hu} \mathrm{Q}$, et al. Exploring the high-performance $(1-x) \mathrm{BaTiO}_{3}-x \mathrm{CaZrO}_{3}$ piezoceramics with multiphase coexistence ( $\mathrm{R}-\mathrm{O}-\mathrm{T})$ from internal lattice distortion and domain features. J Alloys Compd 2021, 853: 157167.

[27] Dobal PS, Katiyar RS. Studies on ferroelectric perovskites and Bi-layered compounds using micro-Raman spectroscopy. J Raman Spectrosc 2002, 33: 405-423.

[28] Janbua W, Bongkarn T, Kolodiazhnyi T, et al. High piezoelectric response and polymorphic phase region in the lead-free piezoelectric $\mathrm{BaTiO}_{3}-\mathrm{CaTiO}_{3}-\mathrm{BaSnO}_{3}$ ternary system. RSC Adv 2017, 7: 30166-30176.

[29] Perry CH, Hall DB. Temperature dependence of the Raman spectrum of $\mathrm{BaTiO}_{3}$. Phys Rev Lett 1965, 15: 700-702.

[30] Zhang YM, Deng HM, Si SF, et al. Band gap narrowing and magnetic properties of transition-metal-doped $\mathrm{Ba}_{0.85} \mathrm{Ca}_{0.15} \mathrm{Ti}_{0.9} \mathrm{Zr}_{0.1} \mathrm{O}_{3}$ lead-free ceramics. J Am Ceram Soc 2020, 103: 2491-2498. 
[31] Tian YS, Cao LJ, Qin PP, et al. Piezoelectric and thermophysical performances of $\mathrm{La}^{3+}$ and $\mathrm{Ir}^{4+}$ co-doped $\mathrm{Ba}_{0.95} \mathrm{Ca}_{0.05} \mathrm{Ti}_{0.94} \mathrm{Zr}_{0.06} \mathrm{O}_{3}$ ceramics. Ceram Int 2019, 45 : 12825-12831.

[32] Chen XL, He F, Wang YL, et al. Significant effects of powder preparation processes on the physical properties of $\mathrm{Bi}_{0.5} \mathrm{Na}_{0.5} \mathrm{TiO}_{3}-0.06 \mathrm{BaTiO}_{3}$ ceramic. J Mater Sci: Mater Electron 2014, 25: 5309-5315.

[33] Bae SH, Kahya O, Sharma BK, et al. Graphene-P(VDF-TrFE) multilayer film for flexible applications. ACS Nano 2013, 7: 3130-3138.

[34] Wang ZX, Huan Y, Feng Y, et al. Design of p-type NKN-based piezoelectric ceramics sintered in low oxygen partial pressure by defect engineering. J Am Ceram Soc 2020, 103: 3667-3675.

[35] Li M, Pietrowski MJ, De Souza RA, et al. A family of oxide ion conductors based on the ferroelectric perovskite $\mathrm{Na}_{0.5} \mathrm{Bi}_{0.5} \mathrm{TiO}_{3}$. Nat Mater 2014, 13: 31-35.

[36] Donnelly NJ, Randall CA. Mixed conduction and chemical diffusion in a $\mathrm{Pb}\left(\mathrm{Zr}_{0.53}, \mathrm{Ti}_{0.47}\right) \mathrm{O}_{3}$ buried capacitor structure.
Appl Phys Lett 2010, 96: 052906.

[37] Wang XP, Zheng T, Wu JG, et al. Characteristics of giant piezoelectricity around the rhombohedral-tetragonal phase boundary in $(\mathrm{K}, \mathrm{Na}) \mathrm{NbO}_{3}$-based ceramics with different additives. J Mater Chem A 2015, 3: 15951-15961.

Open Access This article is licensed under a Creative Commons Attribution 4.0 International License, which permits use, sharing, adaptation, distribution and reproduction in any medium or format, as long as you give appropriate credit to the original author(s) and the source, provide a link to the Creative Commons licence, and indicate if changes were made.

The images or other third party material in this article are included in the article's Creative Commons licence, unless indicated otherwise in a credit line to the material. If material is not included in the article's Creative Commons licence and your intended use is not permitted by statutory regulation or exceeds the permitted use, you will need to obtain permission directly from the copyright holder.

To view a copy of this licence, visit http://creativecommons. org/licenses/by/4.0/. 